\title{
Introduction to the Special Section on Culture and the Environment
}

While for sure culture and environment in the Philippines, taken separately and as a relation, have been the subject of countless studies, a huge area still lies open for inquiries based on perspectives from within, that is to say, from the experience of culture and environment of those who concretely live out the various cultures within the archipelago. These cultures in themselves involve an understanding of the environment and the way indigenous peoples, for example, stand in relation to it.

The fact alone that the Philippines has at least 170 different languages and that each language contains a culture with its own uniqueness, will give us an idea of how much remains untapped in this area of research. For the Tagakolu or Tagakaulo of Eastern Mindanao, for instance, God bears the name of Tyumanem which literally means "the one who planted." One could surmise how such an understanding of the divine that is intimately related to their experience of their natural environment gives rise to, or flows from, a culture whose wealth and uniqueness have much to offer the world at large in terms of understanding our shared cultures and environment.

In this special section on culture and the environment in the Philippines, Dr. Benjamin M. Vallejo, Jr., in his thought-provoking essay, "Pandemic, Anthropause, and Healing the Planet," reflects on the meaning of the disruption caused by the pandemic (called "anthropause") and how it 
presents itself as a possibility to reassess our human existence in relation to nature, and to determine how we are to correct the mistakes of the past and move toward a future that is not just sustainable but is also able to bring about the full flourishing of both the human community and the natural world.

In "The Sustainable Development Goals and the Importance of Cultural Change," Dr. David O'Connor shows us how the Sustainable Development Goals can only be achieved by way of global solidarity, which in turn can only be forged by a cultural shift. It is not without reason that such a shift is being heralded by the youth, as exemplified by the Swedish activist Greta Thunberg, who managed to both disturb and inspire us at the same time.

For his part, the anthropologist and theologian Br. Karl Gaspar, CSsR's piece, "Resistance to Coal Industry's Impact on Mindanao's Ecology," examines the basis of the growing resistance to coal-fired power plants (CFPPs) in Mindanao, citing not just reports by experts but also the reaction of local communities that bear the brunt of the effects of that technology in their lives. Br. Gaspar's analysis is informed not only by the official teachings of the Catholic Church (notably the papal encyclical, Laudato Si) but, even more significantly, by his long years of personal interaction with lumad communities in the region.

Unfortunately, the dominance of science and technology has brought people to view the environment in a materialistic way. Science, on the one hand, is built on observation and measurement and it has become the principal tool to describe the environment. Technology, on the other hand, has separated humans from the environment. Science and technology have reduced the environment to its material dimensions which can be quantified, and therefore be priced. We now routinely calculate the monetary value of the environment. If the predominant view of the environment is materialistic, then culture which is rooted in the environment becomes tainted with this materialism.

The decade of the 2020s may change things. The COVID-19 pandemic is devastating the global economy, and simultaneously, climate change is accelerating in bringing calamities of great magnitude such as forest fires and 
devastating mudslides. Biodiversity continues to decline even as we realize how bad ocean plastic pollution has become. These environmental losses are beyond calculation. Perhaps this is finally the time when we will realize their value.

These essays indeed invite us to take a pause but only so as to guide our actions in the future. As we say, when we take a pause, we take stock of things, step back, regroup, and try to regain our bearings. In this way, the disruption that the pandemic has brought about becomes a necessary one. To the extent that it is necessary and on a deeper level, it is not really a disruption in the negative sense. It is precisely the opportunity to redeem ourselves by recovering the delicate balance that we have lost through the excesses of the modern technological and calculative age. When we get sick, our bodies force us to take a pause by getting weak, by making us stay in bed for us to heal and recover. Our hope is that we make full use of this enforced disruption that is the anthropause in order for our planet to heal.

Remmon E. Barbaza and Fabian M. Dayrit 19 July 2021 